\title{
Analyzing Information in Complex Collaborative Tasks
}

\author{
Lambert Zaad \\ Han University of Applied Sciences \\ Lambert.Zaad@han.nl \\ Thea van der Geest \\ Han University of Applied Sciences \\ Thea.vanderGeest@han.nl
}

\author{
Dick Lenior \\ Han University of Applied Sciences \\ dick.lenior@hotmail.com
}

\author{
Els van der Pool \\ Han University of Applied Sciences \\ Els.vanderPool@han.nl
}

\begin{abstract}
In this article, we present a method for analyzing the communication of people who exchange dynamic and complex information to come to a shared understanding of situations and of the actions planned and monitored by one party, but executed remotely by another. To examine this situation, we analyzed dispatchers working in police dispatch center in a large city in the Netherlands and their communication behavior in three different settings. The results of our analyses answer the question of how collaborative parties should assess an emergency situation in order to decide how to handle the incident in accordance with the procedures. Our results indicate which information must be communicated in order to deal with the current problem during the course of an incident. We will also demonstrate the proposed way of analyzing the communication used here is needed to understand how information is collaboratively handled in complex tasks.
\end{abstract}

\section{Categories and Subject Descriptors}

H5.3.Group and organization interfaces: Computer-supported cooperative work

\section{General Terms}

Human Factors, Design

\section{Keywords}

research method; coordination centers; communication; common ground; information systems; design requirements

Permission to make digital or hard copies of all or part of this work for personal or classroom use is granted without fee provided that copies are not made or distributed for profit or commercial advantage and that copies bear this notice and the full citation on the first page.

Communication Design Quarterly. ACM SIGDOC, New York, USA.

Copyright 2017 by the author.

\section{INTRODUCTION}

Research has shown a lack of communication in coordination centers can cause errors to arise or the consequences of prior errors to be exacerbated. Communication in such situations can, however, be improved in several ways: by training staff, by improving procedures, and by optimizing the IT support. Our research is aimed at the last point. The goal of this research is to set up design requirements that improve the communication-supporting role of the IT systems. The underlying questions examined for this research are:

- What does the operational communication between the coordinating officer and remote personnel look like?

- In particular, how does shared understanding come about between them?

Such shared understanding means the interlocutors give the same meaning to the information exchanged, and that they both know that this is the case. To examine these ideas, we analyzed the communication required for task performance. Following Garner and Johnson (2007), we call this concept operational communication.

To examine this situation, we analyzed three distinct coordination centers, namely:

(1) One of the regional switch and control centers of the Dutch Railways

(2) The emergency room of a hospital in a medium-sized city

(3) A police control room in a large city

This article focuses on the method we used to analyze the operational communication. Our results show which information must be communicated in order to deal with the current problem during the course of an incident. For this process, we compared the information used by the collaborative parties with the information in the information system. This approach revealed the system was mainly designed to record and present static information (e.g., locations, units, incident type), which is not sufficient for dealing 
with the dynamic and situational handling of reports. Moreover, the information presentation does not distinguish between types of incidents, and it is not in line with the information needs during the three phases of addressing an incident. In this article, we will demonstrate the proposed way of analyzing the communication is needed to understand how information is collaboratively handled in complex tasks. Such analysis, furthermore, is the basis for adequate requirements engineering for (re)designing support systems in coordination centers.

\section{CONTEXT OF THE FIELD STUDY IN A POLICE CONTROL ROOM}

To understand the nature of the research reported here, readers must first understand the dynamics affecting communication in the contexts studied by the authors. To address this factor, this section provides a description of the police control room examined in this study. Within this context, individuals regularly perform the following tasks:

- Receiving a request for help, setting up an emergency report, and sending the report to a dispatcher. The operator receives and records urgent telephonic help requests of citizens. The operator requests information from the caller and determines the report's type and priority. Then, the operator sends the digital report to the dispatcher, including priority and additional information.

- Determining the approach, and setting the handling of the incident in motion. The dispatcher determines the approach of the report and sets the handling of the incident in motion; in particular, the deployment of personnel.

- Coordinating the handling of the incident. The dispatcher coordinates the handling of the incident.

- $\quad$ Formally closing the incident. The officer in charge formally closes the incident handling.
The dispatcher is highly dependent on an information system for his tasks (see Figure 1). For determining the course of action he uses the system to interpret the received report based on the type of the report (see Appendix A, Table 8), the location of the incident, and any additional information available. He also uses the system to determine which emergency units are available in the vicinity of the incident. Such a unit consists of two police officers in a car.

Several of these units are continuously present in each district. Specialized emergency units (e.g., police officers with dogs) are also available and can be deployed. As far as possible, the dispatcher keeps sufficient units available for upcoming incidents. After the dispatcher has deployed a unit via the radiotelephone, he or she uses a code in the information system to link the unit to the incident. The deployed units will then receive the available information in the on-board computer of their car. The report type indicates the nature of the incident, but also implicitly refers to the procedure associated with that type of report. For example, in case of a robbery alarm, the units should position themselves in such a way that they cannot be seen from the building, and a unit in civilian clothes should first pass the building to assess the situation. If the report involves a firearm, then other specific security measures and procedures apply.

Coordinating the handling of the incident by the dispatcher, consists of collecting and providing information, managing the units, and, if necessary, deploying additional units. Once a unit has arrived at the incident location, it informs the dispatcher about the situation, and the seriousness of the situation is reassessed in consultation. Next, the dispatcher determines the strategy, and coordinates the remaining of the handling. If necessary, the deployment is modified.

The dispatcher coordinates the handling of five to twenty-five reports at the same time. A protocol describes how communication should take place. If units want to contact the dispatcher, they push a button on their radiotelephone. On his monitor, the dispatcher

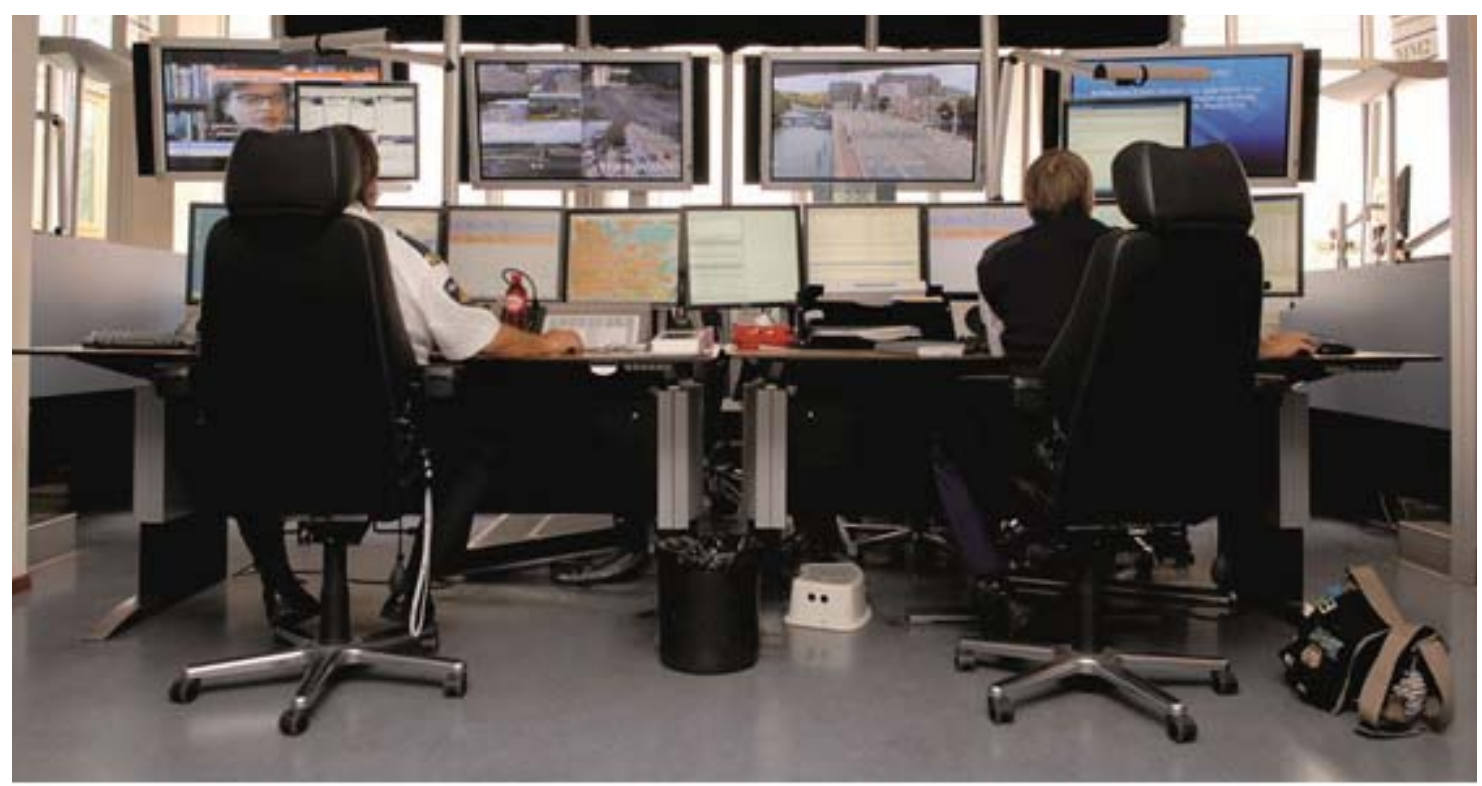

Figure 1: Picture of City Police Dispatch Center. The dispatcher at the right and the assistant at the left. Both individuals are seated behind the information systems and monitors used for determining courses of action. (Picture by Amsterdam Police Dispatch Center) 
sees which units are seeking contact, and he determines the order. All deployed units hear all the conversations that are taking place through the radiotelephone. Therefore, each conversation starts with an explicit indication of whom the call is intended for and who is speaking.

The coordinator has an assistant who maintains contact with other parties, such as the fire brigade, the ambulance control room, or the Dutch Public Works and Water Management Agency. The assistant also helps to enter and process the information in several IT systems, namely a system to monitor incidents and to coordinate units, and a geographic information system that displays all units and incident locations on a map. There are also monitors that show live video images of fixed locations in the city and of the ring road. (These monitors also display images from a helicopter when it is deployed.) In addition, the dispatcher and his assistant have access to auditory communication via radiotelephone and telephone. The operational communication takes place via the radiotelephone, and a multitude of data are exchanged. We will use these data in our later analysis done to derive the mutual information needs.

\section{OVERVIEW OF THE AREA}

Complexity of information was traditionally defined as the freedom of choice between several independent messages (Shannon \& Weaver, 1963). However, in coordination centers, the decisive factor is not merely the complexity of the information, but the complexity of the overall work situation, including the technical and social-organizational structures. To get more insight into the concept of complexity in such settings, Alkemade (1992) studied 11 automation projects carried out in various sectors and interviewed 13 hands-on experts. His study revealed complexity involved: multiplicity, diversity, coherence, simultaneity, and dependence. Alkemade concluded complexity is context-dependent and therefore a generally applicable definition cannot be given.

More recently, a distinction was made between complex and complicated situations (Albers, 2004). In complicated situations the characteristics multiplicity and diversity mainly apply. For example, an instruction manual for repairing an aircraft engine contains much and complex-looking information. However, if the mechanic follows the instructions carefully, he or she will, in principle, achieve his or her goal. The path to the end goal can be determined in advance. This is not the case in complex situations, where, besides multiplicity and diversity, the characteristics coherence, simultaneity, and dependence play a role. The path to a predefined end goal cannot be determined in complex situations. According to Albers, complex situations have the characteristics as presented in Table 1.

Respecting Albers' (2004) statement about impossible completeness, the characteristics as described in Table 1 can still help to characterize the observed task situations in the coordination centers (studied by the authors) sufficiently to set up requirements related to these characteristics: factors for improving the support by existing IT systems as well as IT systems to be developed.

Operational communication in coordination centers has been studied extensively, especially in studies in the field of Computer Supported Cooperative Work (CSCW) and human factors. These showed that stakeholders coordinate their joint work subtly, both verbally and non-verbally (Berndtsson \& Normark, 1999; Heath \& Luff, 1992; Hutchins \& Palen, 1997). Many of these studies were conducted in situations where major incidents, such as wars and disasters, take place (Luokkala \& Virrantaus, 2014; Streefkerk et al., 2014), and where visual contact between parties is usually possible (Berndtsson \& Normark, 1999; Gabris \& Artman, 2004; Heath \& Luff, 1992). Our research, however, studied the ordinary daily task performance in coordination centers, and coordinators did not have visual contact with their interlocutors; they communicated via telephone or radiotelephone. Hence, non-verbal communication between the interlocutors was not possible.

In the human factors literature aimed at the (re)design of coordination centers (e.g., Pikaar et al., 1990; Lenior, 1993), operational communication is often analyzed for design purposes. However, this is mainly done in order to study how often certain issues come up in communication, and whether errors occur. In essence, the tasks are analyzed with a focus on communication. In our study, we also conducted task analyses, but we focused on how the information is exchanged. In other words, we also conducted the analysis on language level.

From this perspective, we examined language-oriented approaches, such as Language/Action Perspective (LAP) and conversation

Table 1: Characteristics of Complex Situations (from Albers, 2004, pp. 35-37)

\begin{tabular}{|c|c|}
\hline No single answer & $\begin{array}{l}\text { "The required information does not exist in a single spot and a single answer, 'the correct } \\
\text { one' doesn't exist. ..." }\end{array}$ \\
\hline Open-ended questions & $\begin{array}{l}\text { "An open-ended question has no fixed answer that can be defined in advance and it } \\
\text { can be difficult, if not impossible, to even state when the question has been answered } \\
\text { completely." }\end{array}$ \\
\hline $\begin{array}{l}\text { Multidimensional } \\
\text { strategies }\end{array}$ & $\begin{array}{l}\text { "A person needs to use an evaluation strategy that takes into account multiple factors } \\
\text { simultaneously, because the information normally comes from sources and can be looked } \\
\text { at in different ways." }\end{array}$ \\
\hline Has a history & "Complex systems have a history, which implies the system has a future." \\
\hline Dynamic information & $\begin{array}{l}\text { "None of the important information has a fixed value, rather it changes continually. Also, } \\
\text { the user's goals and information needs are highly dynamic and are continually refined as } \\
\text { new information is revealed." }\end{array}$ \\
\hline Nonlinear response & $\begin{array}{l}\text { "The response is often nonlinear, meaning it is very sensitive to the initial conditions and } \\
\text { influencing factors." }\end{array}$ \\
\hline
\end{tabular}


Table 2: Interlocutors' Utterances to Express Negative (a-d) and Positive (e-g) Evidence of Understanding During Phone Conversations (from Clark \& Schaeffer, 1987)
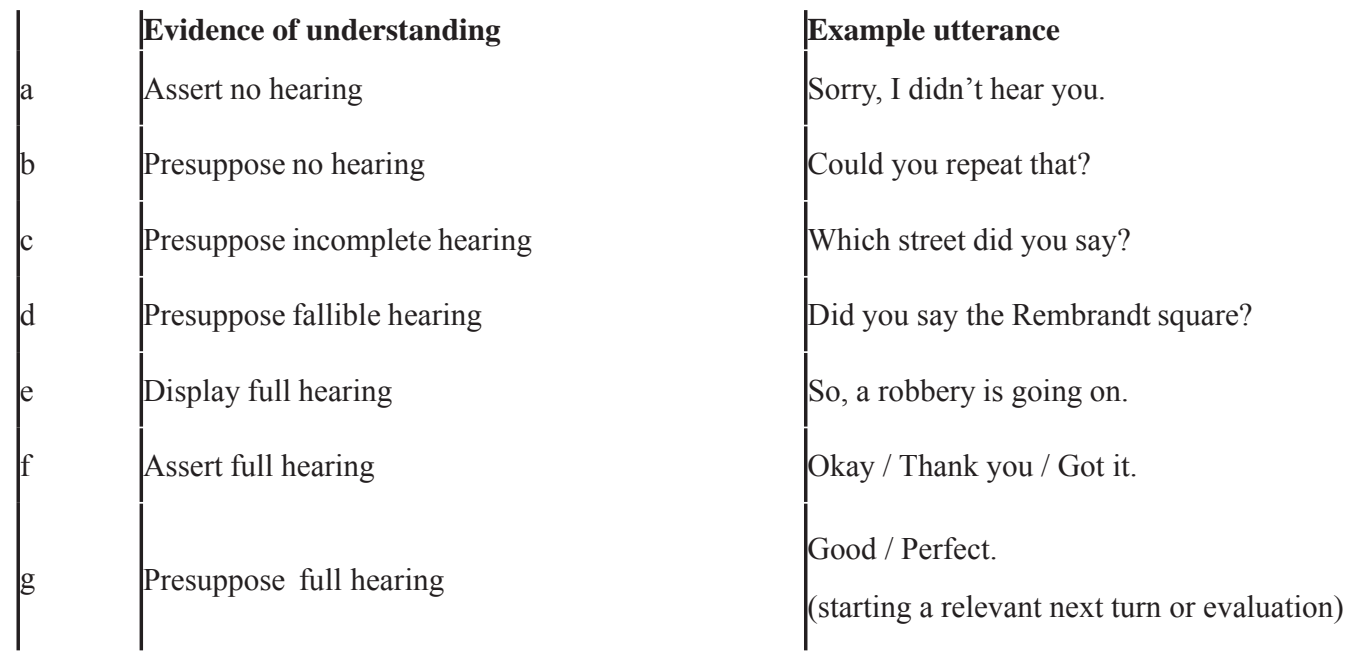

analysis (CA). LAP uses the speech act theory as a basis for the design of information systems. However, according to Suchman (1994), Weigand (2006), and Winograd (2006), that does not do justice to the complexity of the communication process, while this process partly determines the task performance. CA provides a very detailed analysis of the verbal interaction between people and how the interlocutors build that interaction, but the findings are rarely associated with task performance. For that reason, Randall et al. (2007) find CA too detailed to serve as an analytical tool for designing task-support systems.

Because our study is aimed at designing for task support, we used Clark's (1996) common ground theory. Clark links communication with the joint activity (task performance) and the current situation. When applying Clark's framework of analysis, tasks in coordination centers can be regarded as joint activities that are based on the common ground of the parties involved. Common ground is a supposed shared base of knowledge, assumptions, and attitudes that is adequate for performing the current joint activity. In order to maintain and expand common ground, people apply grounding (Clark \& Brennan, 1991), which means that they inform each other about their level of understanding. When communication partners show positive evidence of understanding with regard to a particular joint activity, they have reached shared understanding for that activity (Clark, 1996). Table 2 shows example utterances of negative $(\mathrm{a}-\mathrm{d})$ and positive $(\mathrm{e}-\mathrm{g})$ evidence of understanding when people communicate by telephone (Clark \& Schaeffer, 1987).

We will use this format $(\mathrm{a}-\mathrm{g})$ to discuss the conversation fragments in Tables 4 and 5, and to show how the interlocutors in the police control room give each other positive and negative evidence of understanding.

We used another concept of Clark (1996), namely coordination devices. These increase the predictability within the cooperation: They make the next step in a joint activity more likely. Clark identifies four types:
(1) Explicit agreements
(2) Saliences

\section{(3) Conventions \\ (4) Precedents}

Table 3 lists these coordination devices with short(ened) descriptions, as used by Klein et al. (2005).

In our study, we linked the coordination devices with the task situation. We will illustrate this with conversation fragments that occurred in the police control room.

\section{APPROACH OF THE FIELD STUDY IN THE POLICE DISPATCH CENTER}

The approach described here is aimed at analyzing the communication during the performance of complex tasks in order to infer the information needs of the stakeholders. By linking those information needs with the information that is processed and/or presented in the IT systems, we can verify if the IT can help to improve the support of the communication. The approach of the research consists of three steps described here. In describing these steps, we will also clarify this approach on the basis of the field study in the police dispatch center.

\section{Step 1: Analyzing the Task Performance}

Getting to understand the setting, the activities, and the task performance by making a Hierarchical Task Analysis (HTA; Kirwan \& Ainsworth, 1992) and by conducting contextual interviews (Beyer \& Holtzblatt, 1997).

As a first step, two researchers visited the control room two to three days a week for four months. In practical situations such as these, the actual task performance often does not go according to the plans and procedures, so the experiences of the dispatchers involved are essential. To study these experiences, we conducted contextual interviews with 42 officers (dispatchers, operators, and officers in charge). Almost all of these individuals worked in the control room during those four months when we conducted observations.

We started directly with the contextual interviews to learn the tasks and processes of the dispatch center. First, we concentrated 
Coordination device
Explicit agreements
Saliences
Conventions
Precedents

\begin{abstract}
Description Klein et al. (2005, pp. 153-154)
"Coordinating parties can explicitly communicate their intentions and work out elements of coordination. This category includes, in addition to language, diverse other forms of signaling that have shared meaning for the participants, including signs, gestures, and displays."

"Salience has to do with how the ongoing work arranges the workspace so that the next move becomes apparent within the many moves that could conceivably be chosen [. . .] Coordination by salience is produced by the very conduct of the joint activity itself. It requires little overt communication and is likely to be the predominant mode of coordination among long-standing, highly practiced teams."

"Often, prescriptions of various types and degrees of authority apply to how parties interact. These can range from rules and regulations to less formal codes of appropriate conduct. These less formal codes include norms of practice in a particular professional community as well as established practices in a workplace. Coordination by convention depends on structures outside of a particular episode of joint activity."

"Coordination by precedent is like coordination by convention, except that it applies to norms and expectations developed within the ongoing experience of the joint activity. As the process unfolds, decisions are made about the naming and interpretation of things, standards of acceptable behavior and quality [...] As these arise and develop during the course of the activity, they tend to be adopted as devices (or norms) of coordination for the remainder of the activity."
\end{abstract}

on the global tasks of the dispatch center and as we became more familiar with them we focused more on specific tasks and actions of the dispatcher. In addition, we studied the procedures and made a Hierarchical Task Analysis. A final goal of the step was to obtain a representative sample of communication fragments for the next step in the study. We based this selection on the priority and the type of the report (described in detail in Appendix A).

\section{Step 2: Analyzing the Operational Communi- cation}

Analyzing how the stakeholders create shared understanding during the operational communication and which coordination devices they use.

After studying the linguistically oriented literature, we used parts of the conversation analysis to determine how the mutual information exchange is created. Conversation analysis focuses on typical sequences and patterns in conversation acts. We used these sequences - adjacency pairs - in the analysis to identify the organization of a conversation (Mazeland, 2003). Next, we analyzed the mutual information exchange in the task performance, using Clark's (1996) common ground theory. This approach allowed us to ascertain how shared understanding is created and which coordination devices are used. To do so, we studied the positive and negative evidence of understanding as described in Table 2. Only when the utterance fit category e, f, or $g$ of Table 2 could shared understanding be ascertained. We then analyzed the use of coordination devices as described in Table 3. In combination with the knowledge on task performance that we acquired in Step 1, we could determine the information needs of the interlocutors.

\section{Step 3: Analyzing the IT system}

Analyzing the IT systems that are used and the way in which and the extent to which these support the task performance as can be inferred from the communication analysis.

In this step, we first examined the use of IT resources. (As mentioned previously, the dispatchers have a system to monitor incidents and coordinate units, they have a geographic information system, and they have various monitors for live video images.) We also conducted additional contextual interviews aimed at the use of the information system and involving 10 dispatchers. Additionally, we used structured interviews to asked six dispatchers about their specific uses of and experiences with the system. Furthermore, we studied existing documentation about the systems, and repeatedly talked with a system administrator. Finally, we talked with the system developers separately to discern the technical capabilities of the system in order to consider methods to potentially improve the deployment and coordination of officers.

We compared the information needs in this context with the presence of coordination devices in that setting (see Table 3) as determined in Step 2. By linking the information needs with these coordination devices, we were able to determine what information a dispatcher needs at which moment in the conversation and task performance. We were also able to determine if this information was available and was quickly accessible in the system.

\section{RESULTS}

In this section, we report our findings in a step-by-step manner and as relating to the sequence of the performed method.

\section{Step 1: Analyzing the Task Performance}

The task analysis and contextual interviews gave us a good understanding of the tasks that are performed in the control room, especially those tasks performed by the dispatcher. In this context, the police distinguish between priority-1 and priority-2 reports. Priority-3, -4 , and -5 reports also exist, but these occur rarely and do not concern emergencies; the dispatcher only needs to take note of these internal police reports. We therefore excluded such reports from the analysis.

Priority-1 covers three incident types:

1) A caught-in-the-act situation with a high chance of catching the perpetrator; 
2) An incident with much social impact (muggings, robberies, violence);

3) A report about a life-threatening situation (resuscitation, accidents with injury).

Priority-2 relates to incidents such as shoplifting, burglary without catching the burglar(s) in the act, a traffic accident without serious injury, or vandalism.

The differences between these two priorities is reflected by the number of conversations held during the handling of an incident. The 153 selected priority-1 incidents we studied elicited 1765 conversations between the dispatcher and the involved units, whereas the 101 selected priority-2 incidents we studied elicited 635 conversations. In addition to the number of conversations, the speed of the speech of the dispatcher is different. Fragment 1 and 2 show the initial deployment of emergency units by the dispatcher.

Here, Fragment 1 concerns a priority-1 incident and Fragment 2 a priority- 2 incident. Both fragments lasted roughly 20 seconds.
The dispatcher is more directive during a priority- 1 incident and he speaks faster. By using the transcription conventions of conversation analysis, one can visualize non-verbal aspects of speech, like speed and emphasis that display meaningful aspects of the interaction (See table 9 in Appendix B for an explanation of the notations of the conversation analysis conventions.)

In Albers' (2004) terminology, priority-1 reports are complex because of the urgency, dynamism, and unpredictability. Priority-2 reports are complicated, because they are less urgent and less dynamic, and more predictable in terms of handling. Figure 2 gives a global overview of the tasks of the handling two variants of a priority- 1 report on the left and the handling of a priority-2 report on the right.

This first step of our study led to insight in the task situation, but also to a representative selection of conversation fragments for further analysis in Step 2 as described earlier. For this first step, we basically used two "inputs" for this selection, namely the priority and the type of the report (see Appendix A for a description of the

\begin{tabular}{|c|c|}
\hline Dis & $>$ AS forty eight zero one?< \\
\hline $\mathrm{Pu}$ & >HQ forty eight zero one?< \\
\hline Dis & $>$ FORTY eight< zero one= \\
\hline Dis & $>=I^{\prime} l l$ be right back< (.) stay tuned \\
\hline \multirow[t]{2}{*}{ Dis } & >forty six zero one< $\uparrow$ over \\
\hline & $(2.3)$ \\
\hline $\mathrm{Pu}$ & >forty six zero one< $\uparrow \mathrm{HQ}$ ? \\
\hline Dis & forty six zero one, for you <and the forty eight> (.) zero one (.) \\
\hline Dis & >I have a burglary red-handed for you \\
\hline Dis & it is at the John Doe Quay, opposite number hundred <sixteen> \\
\hline Dis & and it are pe- two persons breaking (.) <into> a squat \\
\hline Dis & $\uparrow$ over. \\
\hline \multicolumn{2}{|r|}{$\begin{array}{l}\text { Abbreviations: } \mathrm{Dis}=\text { dispatcher, } \mathrm{PU}=\text { police emergency unit, AS = Attention } \\
\text { Service Message, } \mathrm{HQ}=\text { Headquarters } \\
\text { Note: All names and addresses in the fragments were anonymized }\end{array}$} \\
\hline
\end{tabular}

\section{Fragment 1: Opening Call for a Priority 1 Incident}

\begin{tabular}{|l|l|}
\hline Dis & and then, AS twenty one zero one $\uparrow$ here $\uparrow$ the HQ? \\
\hline Pu & >twenty one zero< one? \\
\hline Dis & twenty one zero one= \\
\hline Dis & =for you noise disturbance (.) \\
\hline & e: : > No< something very different \\
\hline & Burglary into a home not red handed at the John Doe Street hundred forty one \\
\hline & $(1.8)$ \\
\hline Pu & got it, on our way \\
\hline Dis & <yes on the way > >ut< \\
\hline
\end{tabular}

\section{Fragment 2: Opening Call for a Priority 2 Incident}


selection process). We eventually identified 253 reports that varied in priority. The dispatcher communicated about these reports in 2399 conversations. This number is so high, because he has many short conversations with various units. For each of these 2399 conversations we documented the

- Incident number (automatically assigned);

- Report classification and sub-classification;

- $\quad$ The granted priority;

- $\quad$ Type of police unit;

- Conversation objective (based on the given reason for the conversation);

- $\quad$ Person who initiated the conversation;

- Duration of the conversation.

We also documented the date and time of each conversation, in order to be able to easily retrieve the conversations in the audio archive of the control room.

From the initial 253 reports, we selected reports that varied in priority and type, and that illustrated the daily work in the control room. The final selection contained 13 priority- 1 and priority- 2 reports, of which we analyzed all 228 conversations in terms of content in Step 2.

\section{Step 2: Analyzing the Operational Communi- cation}

The content analysis of the operational communication showed us how the dispatcher and his interlocutors achieve shared understanding, and which coordination devices were used in that process. Tables 4 and 5 illustrate this on the basis of two conversation fragments. These analyses also show how the parties handled the complexity of their task. We chose the fragment in Table 4, because it characterizes the dynamics of the initial situation (a child calls in distress) and much information is exchanged between the dispatcher and three separate units in a short time.

In Table 4, column 1 shows the numbering per utterance, column 2 shows the speaker, and column 3 shows the utterance transcribed. Column 4 shows, per utterance and when applicable, which evidence of understanding was given (see Table 2; a-d in the Table indicate negative evidence of understanding, and $\mathrm{e}-\mathrm{g}$ indicate positive evidence of understanding). Column 5 shows which coordination device (see Table 3) was used. In some cases, we added a brief interpretation on our part. When applicable, the interpretation is further explained in Table 4 (indicated with an asterisk).

We chose the fragment in Table 5 to show that the dispatchers need to keep track of who is doing what concerning multiple ongoing incidents. The fragment also shows a transition from negative to positive evidence of understanding due to a short malfunction in the mutually used information system; it is for this reason that the unit asks for the report again, and the dispatcher accidentally sends the wrong report.

This second fragment shows how the stakeholders handle situations when there is no shared understanding. In almost all cases, the lack of shared understanding was restored in the same conversation. In all the conversations that we analyzed, we only found one case where both the previously correctly communicated situation no longer applied and this change was not noticed. The incorrect communication had indicated that three suspects had been arrested, but afterwards, it became clear that only two suspects had been arrested. The confusion had arisen because one suspect had taken his coat off and therefore no longer matched the initial description. In a remarkable second example of non-shared understanding, an incorrect location of a shooting was communicated in the second instance, but the unit had remembered the first, correctly communicated location.

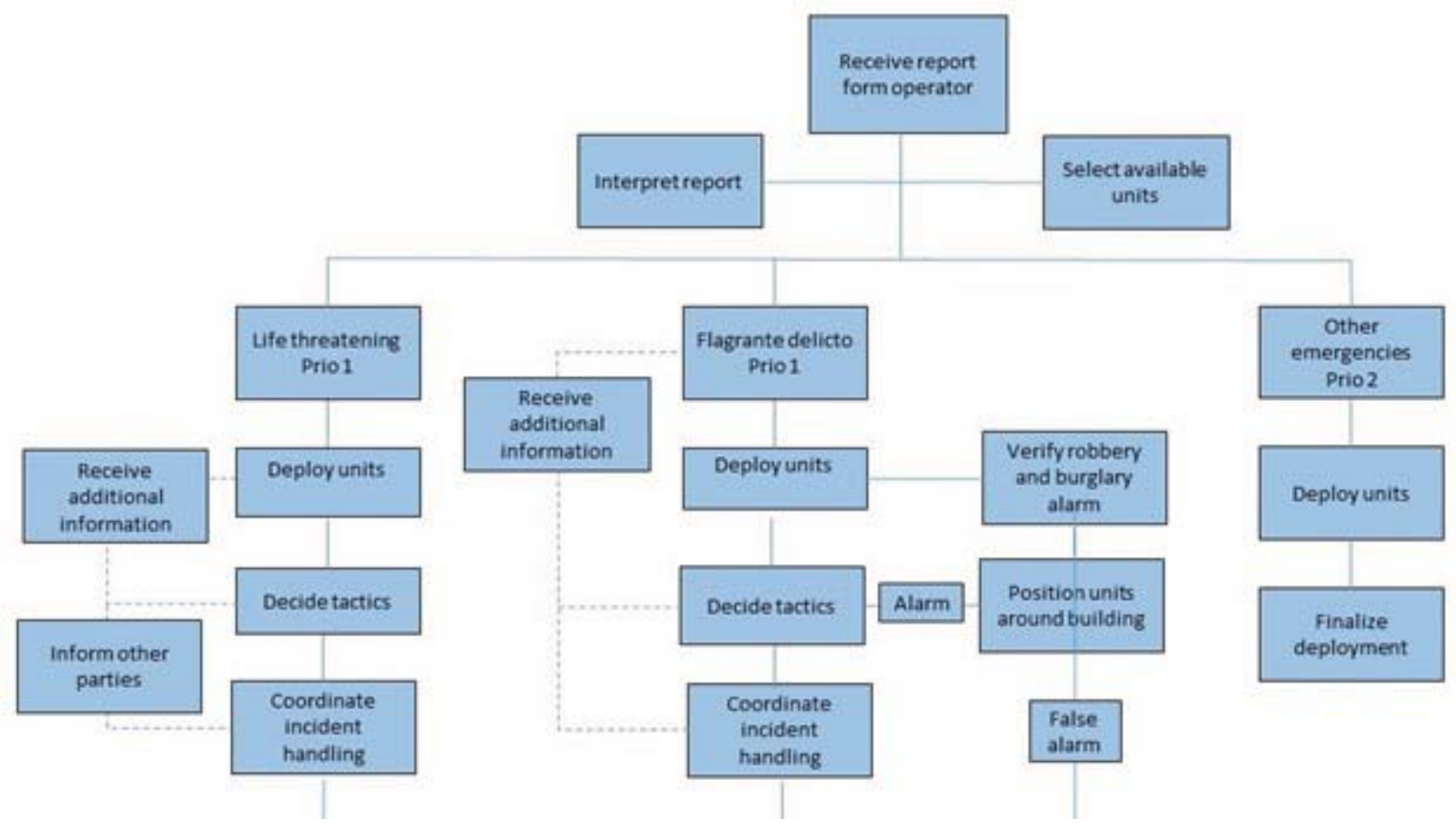

Figure 2: Global Overview of Tasks for the Position of Dispatcher in the Police Control Room. (Figure created by author) 
Fragment 3 shows an example of how explicit agreements and conventions are used in the operational communication. When a unit reported they had arrived at the scene (line 1), the coordinator requested to tell him when it was safe enough to allow paramedics at the scene. These paramedics were waiting outside because the police must guarantee a safe workplace before they enter the scene. The explicit acceptance of the request in line 4 completes the request. Moreover, the wording in line 3 is a convention that refers to a procedure.

The linguistic analysis of all 228 conversations provides insight into how the coordination takes place during task performance. Due to the complexity of the incident handling, the stakeholders go about this process step by step. By mapping the use of grounding, it became clear how the cooperating parties do this step by step and where, per step, shared understanding is reached.

By subsequently mapping the coordination devices, it became clear how the task performance is coordinated via the communication. This mapping of the coordination devices made the following clear about the use of coordination devices:

- The explicit agreements were mainly used to instruct units to keep the dispatcher informed of the progress. The other agreements concerned organizing extra support.

- Conventions were used to inform each other of the current situation or impending actions. This is done by: (a) mentioning the incident type, and (b) explicitly or implicitly referring to procedures. In addition, conventions were used for (c) the use of the radiotelephone, namely for identifying the sender and receiver by unit number or abbreviation.

- All precedents were used to identify a specific incident on the basis of the report type and/or the incident location. See line 8 and 11 of fragment 2 for an example.

- The use of saliences was related to the use of the radiotelephone. Because all units hear everything that is being said via radiotelephone, they can refer to what has previously been said by others via radiotelephone when they seek contact themselves. See line 15 of fragment 1 for an example.

The analysis of the use of coordination devices led to two general findings: Priority-1 and priority-2 reports are handled differently, and dealing with the complexity of priority-1 incidents makes it necessary for the parties to combine a wide range of different types of information.

The first general finding is that the handling of priority 1 and priority 2 differs in two ways. First, the handling of priority-1 reports differs from the handling of priority-2 reports in approach and information needs. A priority-1 report concerns an urgent need, several involved parties, an unpredictable course of the incident handling, and a need for strong situational action. This requires much coordination and thus, communication between the dispatcher and the parties involved. A priority-2 report concerns incidents with a less urgent need, and the handling of such reports is more predictable. Such a report can be coordinated well on the basis of existing procedures. As a result, less coordination is needed, and the operational communication is more focused on acting in accordance with procedures. In Albers' (2004) terminology, a situation with a priority-1 report can be referred to as complex, and a situation with a priority-2 report can be referred to as complicated.
Second, the handling of priority-1 reports differs from the handling of priority-2 reports in each phase. We distinguish three phases:

1) The initiation phase that starts when a report comes in and is being interpreted;

2) The coordination phase that starts when the unit is on site and can describe the situation well;

3) The completion phase that starts when the end of the incident is in sight, namely when the perpetrator(s) has been arrested or obviously escaped, when the greatest need is over, or when non-emergency units take over the incident.

The completion phase can be coordinated well according to the procedures due to the decreased urgency and the increased predictability; it is a complicated, rather than a complex situation (cf. Albers, 2004).

In case of a priority-1 report, the dispatcher collects and interprets specific information in the initiation phase, such as report type, incident location, availability of units, and any additional information about the incident. Next, the dispatcher deploys the units that need to handle the incident. In the coordination phase, the first unit on site informs the dispatcher about the current situation, and they jointly determine a strategy for handling the incident. This handling is iterative and requires continuous coordination for which information about the current situation is needed.

During the completion phase, the dispatcher uses information that is aimed at handling the incident according to procedure. On this basis, the dispatcher can estimate when the involved units will be available again. In some cases, the dispatcher informs other parties about the progress of the completion. The complexity of the incident has been reduced in this third phase, and the situation is now complicated.

In handling priority-2 reports, the dispatcher is particularly active in the initiation phase. He or she needs the same information for handling priority-2 and priority-1 reports, but the time pressure is lower when handling a priority-2 report. In the coordination phase that follows, the dispatcher has little contact with the deployed units; hence, that phase is skipped. The completion phase consists of receiving a message that the incident has (almost) been completed.

The second general finding of the operational communication was that dealing with the complexity of priority- 1 incidents makes it necessary for the parties to combine different types of information. On the one hand, information is needed to invoke the proper procedures for such a report. This is basically "static," generic information that reflects the procedures and protocols associated with the type of incident, such as report type, characteristics of a report, and location. Conventions are used here. On the other hand, "dynamic," situational information is needed about the specifics of the incident. Each specific report has its own situational circumstances that influence the course of the incident. This, in turn, influences the way the procedures are applied. Often, explicit agreements, precedents, and saliences are used here.

Figure 3 illustrates the two general findings. On the left, it shows the three phases that are associated with the handling of a priority-1 report and the (sub-)tasks performed in each phase. The funnel shape in the initiation phase and the completion phase of an incident indicates that less and less information is exchanged. The shape in the coordination phase reflects the dynamic information exchange in this phase: Continuous coordination takes place to create an upto-date picture of the situation in order to be able to determine the next step of the handling. 
Table 4: Conversation Fragment 1, Including the Interpretations as Used in the Analysis

\begin{tabular}{|c|c|c|c|c|}
\hline \multicolumn{2}{|c|}{ Fragment 1} & \multirow{2}{*}{$\begin{array}{l}\text { Utterance } \\
\text { AS >twenty one < zero one here the } \mathrm{HQ} \\
\text { Over }\end{array}$} & \multirow[t]{2}{*}{ Evidence of } & \multirow{2}{*}{$\begin{array}{l}\text { Coordination device and interpretation } \\
3 \text { conventions: identifying speaker and addressee: AS, } \\
2101, \mathrm{HQ}\end{array}$} \\
\hline 1 & Dis & & & \\
\hline 2 & & $(3.0)$ & & \\
\hline 3 & Dis & $\begin{array}{l}\text { AS >twenty one }<\text { zero one here the } \mathrm{HQ} \\
\text { Over= }\end{array}$ & & $\begin{array}{l}3 \text { conventions (Repeat): unit } 2101 \text { doesn't respond } \\
\text { quickly; dispatcher repeats because of severity of the } \\
\text { incident }\end{array}$ \\
\hline 4 & Dis & $=$ out $=$ & & Convention: protocol of radiotelephone use \\
\hline \multicolumn{5}{|c|}{ New Call } \\
\hline 5 & Dis & $\begin{array}{l}\text { =AS twenty two zero one here the HQ } \\
\text { over }\end{array}$ & & $\begin{array}{l}2 \text { Conventions: } 2201 \text { and HQ. Dispatcher calls other } \\
\text { unit; see note }{ }^{* 1}\end{array}$ \\
\hline 6 & PU & $<\mathrm{HQ}>$ the twenty two zero one? & $\begin{array}{l}\text { [e] Display } \\
\text { full hearing }\end{array}$ & \\
\hline 7 & Dis & $\downarrow$ John Doe Street thirty six $\downarrow$ level one $=$ & & \\
\hline 8 & Dis & $\begin{array}{l}=\text { a child on the phone }>\text { says }<\text { her mother } \\
\text { got } \downarrow \text { stabbed } \downarrow \text {, }\end{array}$ & & Convention: description of incident type; see note ${ }^{* 2}$ \\
\hline 9 & Dis & she locked herself in the bathroom, & & Convention (continuation line 8) \\
\hline 10 & Dis & you have permission ove:r? & & $\begin{array}{l}\text { Convention: permission to use flashing lights and } \\
\text { siren }\end{array}$ \\
\hline 11 & PU & $(>$ well<)the twenty one is also here e:h & $\begin{array}{l}{[g] \text { resuppose }} \\
\text { full hearing }\end{array}$ & $\begin{array}{l}\text { Salience: sign of understanding priority level of } \\
\text { incident (level 1) }\end{array}$ \\
\hline 12 & PU & I assume we go there with two cars=hq? & & $\begin{array}{l}\text { Convention: related to Convention in line } 8 \text { (incident } \\
\text { type) }\end{array}$ \\
\hline 13 & Dis & you both have permission, & $\begin{array}{l}{[g] \text { resuppose }} \\
\text { full hearing }\end{array}$ & \\
\hline 14 & Dis & $\begin{array}{l}\text { twenty one and twenty two zero one } \\
>\text { on their way }<\text {, out }=\end{array}$ & & Convention: Status update of both units \\
\hline 15 & PU & $((0025$ request to speak $))$ & & $\begin{array}{l}\text { Convention: Protocol of radiotelephone use Salience: } \\
\text { note }{ }^{* 3}\end{array}$ \\
\hline 16 & Dis & $=$ the $\downarrow$ double $\downarrow$ zero twenty five, & $\begin{array}{l}{[g] \text { resuppose }} \\
\text { full hearing }\end{array}$ & $\begin{array}{l}\text { Convention: number of unit (unit with police dog) } \\
\text { note }{ }^{* 4}\end{array}$ \\
\hline 17 & Dis & $\begin{array}{l}\text { you also go to the John Doe Street? } \\
\text { Over }\end{array}$ & & Precedent: street name is used to identify report \\
\hline 18 & PU & $\begin{array}{l}>\mathrm{HQ}<\text { good evening=the double zero } \\
\text { twenty five rides along indeed }\end{array}$ & $\begin{array}{l}\text { [e] Display } \\
\text { full hearing }\end{array}$ & Convention: status update of unit \\
\hline 19 & Dis & YES! >perfect $<$, thank $\downarrow$ you $\downarrow$ & $\begin{array}{l}\text { [f] Assert full } \\
\text { hearing }\end{array}$ & \\
\hline
\end{tabular}

Abbreviations: Dis = dispatcher, $\mathrm{PU}=$ police emergency unit, $\mathrm{AS}=$ Attention Service Message, $\mathrm{HQ}=$ Headquarters

Note: All names and addresses in the fragments were anonymized

*1. The unit that was called first, has not responded yet, so the dispatcher calls another unit; he needs to adjust his strategy (Albers, 2004).

*2. The description of the incident type in lines 8 and 9 implicitly refers to the manner in which the unit should approach the situation; that is the convention. The description is still brief, so the interlocutors should work with what Albers (2004) calls dynamic information and open-ended questions. The (brief) description also reflects the history of the incident, on which the units base their preliminary strategy; they may adjust this strategy once it becomes known whether or not the burglar is still in the house.

*3. A contact request so soon after a new report usually means that this unit prefers driving to the incident as well: a convention. This is a response to the report that was just communicated via radiotelephone: a salience. Line 17 shows that the dispatcher also interprets this contact request, the convention, in this manner.

*4. This unit's number indicates that the unit has a police dog, which is very desirable with this type of report. Deploying a dog is an adjustment of the strategy (Albers, 2004). 
Table 5: Conversation Fragment 2, Including the Interpretations as Used in the Analysis

\begin{tabular}{|c|c|c|c|c|}
\hline \multicolumn{2}{|c|}{ Fragment 2} & \multirow{2}{*}{$\begin{array}{l}\text { Utterance } \\
\text { >you< have put another in my e:h } \\
\text { screen (.) pickpocketing }\end{array}$} & \multirow[t]{2}{*}{$\begin{array}{l}\text { Evidence of } \\
\text { understanding }\end{array}$} & \multirow{2}{*}{$\begin{array}{l}\text { Coordination device and } \\
\text { interpretation } \\
\text { Convention: referring to the procedure } \\
\text { that the dispatcher sends information } \\
\text { to on-board computer } \\
\text { Precedent: incident type to identify } \\
\text { report }\end{array}$} \\
\hline 1 & $\mathrm{Pu}$ & & & \\
\hline 2 & & $(2.5)$ & & \\
\hline 3 & Dis & $\begin{array}{l}\text { YES, but you are talking about a scooter, } \\
\text { so that is why I assume you are talking } \\
\text { about that report about eh? }\end{array}$ & $\begin{array}{lr}{[g]} & \text { Presuppose } \\
\text { full } & \text { hearing }\end{array}$ & $\begin{array}{l}\text { Precedent: "a scooter" is used to identify } \\
\text { a specific incident; note }{ }^{* 1}\end{array}$ \\
\hline 4 & Dis & $\begin{array}{l}\text { >which other report do you mean } \\
\text { over<? }\end{array}$ & & \\
\hline 5 & $\mathrm{Pu}$ & (1.5) & & \\
\hline 6 & $\mathrm{Pu}$ & yes, everything is mixing $\downarrow$ together & & $\begin{array}{l}\text { Salience: referring to rush of the } \\
\text { moment; note }{ }^{* 2}\end{array}$ \\
\hline 7 & & I am still at the eh crime scene $j=$ & $\begin{array}{l}{[g] \text { Presuppose }} \\
\text { full hearing }\end{array}$ & $\begin{array}{l}\text { Convention: referring to his current } \\
\text { activity }\end{array}$ \\
\hline 8 & Dis & = J- John Doe Street & & $\begin{array}{l}\text { Precedent: Using location to identify } \\
\text { specific incident }\end{array}$ \\
\hline 9 & Dis & o::h that, & $\begin{array}{l}{[f] \text { Assert full }} \\
\text { hearing }\end{array}$ & \\
\hline 10 & Dis & $\begin{array}{l}\text { no, because there is also an incident in } \\
\text { your eh are::a (.) about a scooter that } \\
\text { drives away, }\end{array}$ & & $\begin{array}{l}\text { He explains what caused his } \\
\text { misunderstanding }\end{array}$ \\
\hline 11 & Dis & $\begin{array}{l}\text { but you are still busy with that } \\
\text { shooting }\end{array}$ & $\begin{array}{l}{[g] \text { Presuppose }} \\
\text { full hearing }\end{array}$ & $\begin{array}{l}\text { Precedent (continuation line 8): type } \\
\text { of report used to identify specific } \\
\text { incident }\end{array}$ \\
\hline 12 & & I will send you that report over & & $\begin{array}{l}\text { Explicit Agreement: the dispatcher } \\
\text { promises to send the information }\end{array}$ \\
\hline 13 & $\mathrm{Pu}$ & $(1.8)$ & & \\
\hline 14 & Dis & $\downarrow$ thank you $\downarrow$ HQ & $\begin{array}{l}{[g] \text { Presuppose }} \\
\text { full hearing }\end{array}$ & Explicit Agreement (continuation line 11) \\
\hline 15 & $\mathrm{Pu}$ & you 'r welcome, forty eight zero one & $\begin{array}{l}{[g] \text { Presuppose }} \\
\text { full hearing }\end{array}$ & Convention: No. to identify addressee \\
\hline
\end{tabular}

Abbreviations: Dis = dispatcher, $\mathrm{PU}=$ police emergency unit, $\mathrm{AS}=$ Attention Service Message, $\mathrm{HQ}=$ Headquarters

Note: All names and addresses in the fragments were anonymized

*1 The dispatcher explicitly states that he realizes there was no shared understanding; this is the basis for recovery. As a cause, he mentions the reference to a scooter (precedent). Line 4 shows that at this moment, he does not know yet in which incident this unit is involved; grounding takes place, which leads to shared understanding in line 9.

*2 This utterance refers to the dynamics and high information load of the work of a dispatcher. The unit becomes aware of this via the radiotelephone, and refers to it: a salience. 


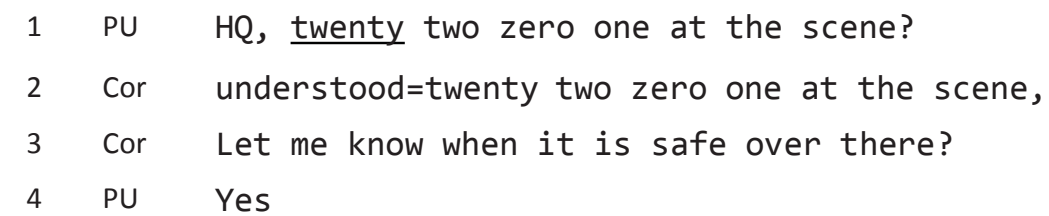

Mapping the use of coordination devices brought to light how different kinds of information are used in combination. The right part of Figure 3 shows which coordination devices were used per phase in the 228 analyzed conversations, and how often. The "distribution" of the coordination devices differs per phase. In Albers' (2004) terms, the first two phases of an incident are referred to as complex; the coordination devices are used to create a joint, upto-date picture in order to be able to determine the most appropriate action. The coordination devices show that dynamic, situational information is combined with static, generic information that refers to the procedures in force. The completion phase of an incident can be referred to as complicated. The coordination devices are now mainly used to refer to the procedure in force; to this end, the conventions are used. Situational information is exchanged less often.

For the sake of completeness, we iteratively conducted the analysis as described previously for a single incident. However, as mentioned before, the dispatcher coordinates multiple reports simultaneously, so multiple processes as described earlier occur simultaneously as well. This increases the complexity of the situation.

\section{Step 3: Analyzing the IT system}

The purpose of this third step was discovering how and to what

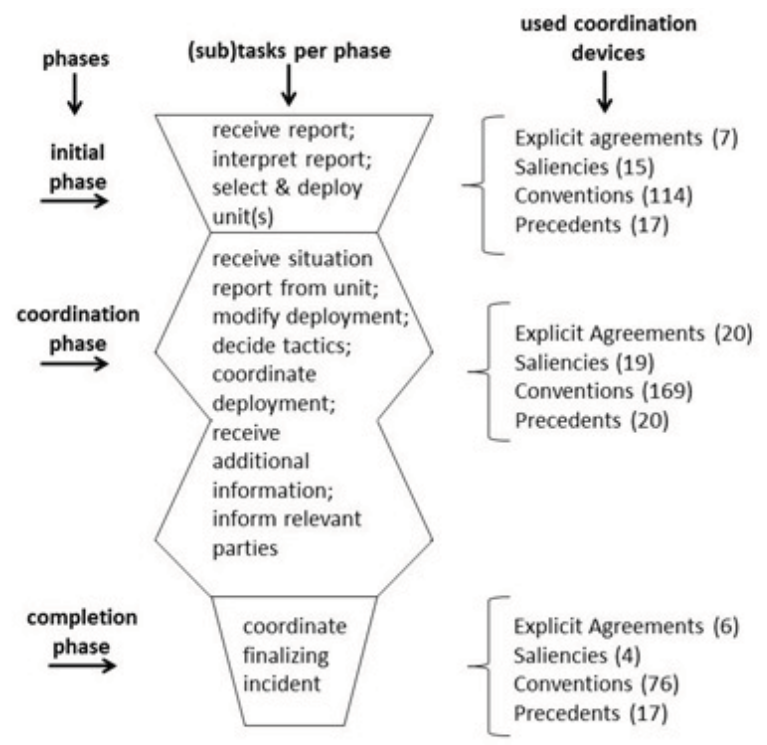

Figure 3: Phases in the Handling Of Priority-1 Reports with Accompanying (Sub-)Tasks and Number of Used Coordination Devices. (Figure created by author) extent the information exchange is supported by the information system during the operational communication. The transcription of the conversations took place at the dispatch center. This allowed us to be present at the actual handling of incidents that were similar to the ones we were transcribing. We regularly returned to the dispatchers and sat behind them while they were executing their tasks. By observing and asking them about their actions and their use of the main application, we gained a deeper understanding of their task performance, and how the application' capabilities correspond to it. In the following we first will briefly describe the system. Next, we will show which information is present in the system, and how that information is used during the handling of an incident.

The IT system has two monitors; one shows a Unit overview and the other shows information of all reported incidents. When the dispatcher selects a report, this report is displayed on new windows on the same monitor. This window is called the "work screen" (see Figure 4). Here, the dispatcher can read and enter information about the report. This screen consists of several windows that contain specific information about the incident report. In Figure 4, these windows are indicated with a frame and a number.

Based on the type of report and the full unit overview (on a separate, second monitor), the dispatcher determines the deployment. Dispatchers "connect" units to the report via the input window from frame $4 \mathrm{~b}$. These units are then deployed and receive the information recorded in frame 3 on their on-board computer of their car.

The contextual interviews during the coordination phase reveal that the dispatchers use this screen intensively, especially the parts in frames $4 \mathrm{a}$ and $4 \mathrm{~b}$. However, they state that it is difficult for them to search for information in 4 a during dynamic incidents. In the first place, because of the small size of the window, it has a fixed size of roughly an eighth of a 19-inch monitor. Secondly, all parties involved in an incident (dispatcher, assistant, unit, and operator) can enter information in the system that is presented in this window, so looking for specific information requires extensive scrolling. Besides, the system automatically records who enters which information when, and then adds this metadata to frame $4 \mathrm{a}$. The structured interviews made clear that dispatchers find it annoying that the window automatically jumps to new information as soon as it is entered by one of the parties involved, because it hinders their own search for information in that particular window.

The analysis and contextual interviews revealed that in the initiation phase of an incident, dispatchers use the information from the screen as follows:

- What happened and where? (frame 3)

- What unit is available or can be made available? (second monitor)

- What is the current location of the units? (second monitor) 
- $\quad$ Registering the deployed units. (frame $4 b$ )

- Communicating any additional information. (frame 4a)

During the coordination phase, dispatchers mainly use and record the following information:

- The units involved. (second monitor and/or frame 1)

- The agreements that have been made and/or protocols that concern the current deployment (frame 4a)

- The changes and/or new information concerning the current report. (frame $4 \mathrm{a}$ )

- The up-to-date search information, such as description, license plate, or walking direction. (frame $4 \mathrm{a}$ )

- The current and planned activities of the units involved. (frame 4a)

- The availability and location of other emergency units. (second monitor)

During the completion phase, dispatchers use the following information:

- The status update of the units. (second monitor)

- $\quad$ Specific information about the incident. (frame 4a)
This overview shows that frame $4 \mathrm{a}$ despite the fact that it is an unstructured text field that takes only $12 \%$ of the display and is by far the most used part of the display. It is the focus of all reading and writing activities of all parties, for both those working in the dispatch center and those remotely handling the incidents.

\section{CONCLUSION AND DISCUSSION}

\section{Conclusion}

An analysis of the tasks and practices of the dispatcher, in combination with a linguistic analysis of the oral communication that is based on Clark (1996), provided insight into how the collaborating parties perform their tasks. Step 2 of the method presented here allowed us to determine how the professionals create shared understanding. The coordination devices in the communication showed that the task performance is mutually coordinated. These also showed which information is needed in the course of the incident handling. By linking these information needs with the use of the current information system, it became clear where the supporting system does not fully support the desired task performance. This is illustrated in Figure 5, which shows the following per phase:

a) The (sub-)tasks that are performed by the dispatcher;

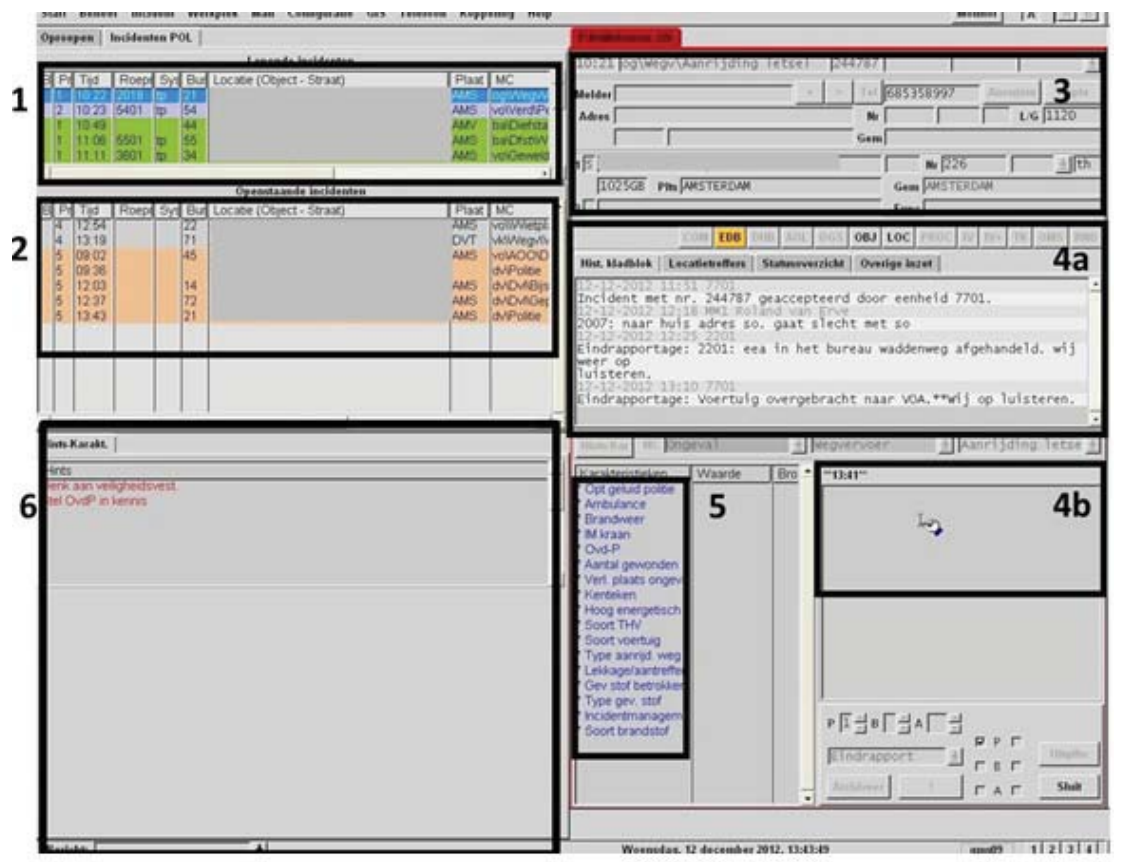

Figure 4: Work Screen for a Specific Report. (Screenshot provided by Amsterdam Police Dispatch Center, edited by author) Frame 1: A compressed view of all active (deployed) units.

Frame 2: A compressed summary of incidents for which no units have been deployed yet.

Frame 3: Incident information as entered by the operator when the report came in.

Frame 4a: Information that was entered during the handling of the incident, by the operator, the dispatcher, and the units involved.

Frame 4b: The input window for the information that is shown in frame $4 a$.

Frame 5: A display window for characteristics that are allocated to the incident according to a set protocol. This is often done automatically by the system, based on the report's classification. The operator can also enter additional characteristics of the report when the report comes in.

Frame 6: Additional information that is related to the characteristics in frame 5, such as advice on the use of a bulletproof vest. 
b) The information needs of the dispatcher;

c) Which information is used by the system.

Similar to Figure 2, the shape in Figure 5 (see column a) represents the dynamics of the information exchange. The rectangular shape on the right illustrates that the information that is recorded and presented only increases during the incident handling, and that the information that is not used (anymore) remains prominently visible on the screen.

The current system mainly presents static, generic information, such as location, time, incident type, and standard procedural details (frames 1, 2, 3, 5, and 6 in Figure 4). With this information, the dispatcher must quickly form a picture of the incident and the location. Because the system hardly offers possibilities for processing dynamic, situational information, we can conclude that the (sub)tasks are supported poorly in the coordination phase. After all, from the moment a unit is on site and informs the dispatcher about the current situation (beginning of coordination phase), an ongoing coordination process follows, in which the dispatcher must quickly form an up-to-date picture in order to determine the continuation of the handling. This information is usually in the memory of the dispatcher and/or "hidden" in frame 4a, as shown in Figure 4. In addition, the complexity increases, because the dispatcher needs to have dynamic, situational information ready of multiple, simultaneously occurring incidents.

The use of coordination devices showed the following: A large part of the information exchange takes place on the basis of conventions. This concerns static, generic information, such as unit numbers and references to procedures. This information can be found somewhere in the system, but it is not easily accessible. Therefore, dispatchers largely retrieve this information from their own memory.

The precedents belong to the category situational information. The analysis showed that this dynamic, situational information is needed throughout the handling, but that it is not easily accessible in the current system, especially in frame $4 \mathrm{a}$ in figure 4 . Here, too, the dispatchers rely on their own memory. Saliences refer to crucial information, especially in the first two phases of the handling. These are often implied references from the units to their intended contribution to an incident handling. Even though explicit agreements strongly influence the mutual coordination, these are not recorded in the system during an incident handling. However, this is necessary, especially since many parties may be involved, and sometimes even multiple dispatchers may be involved when the handling takes a long time.

\section{Design Requirements}

Our ultimate goal is to improve the communication-supporting role of IT in order to reduce the risk of wrong decisions during critical situations. The findings from the study in the police control room are confirmed by the two other field studies in which we also applied the method presented here. These similar findings form the basis for a number of design requirements (see Table 6). Applying these requirements will increase the communication-supporting

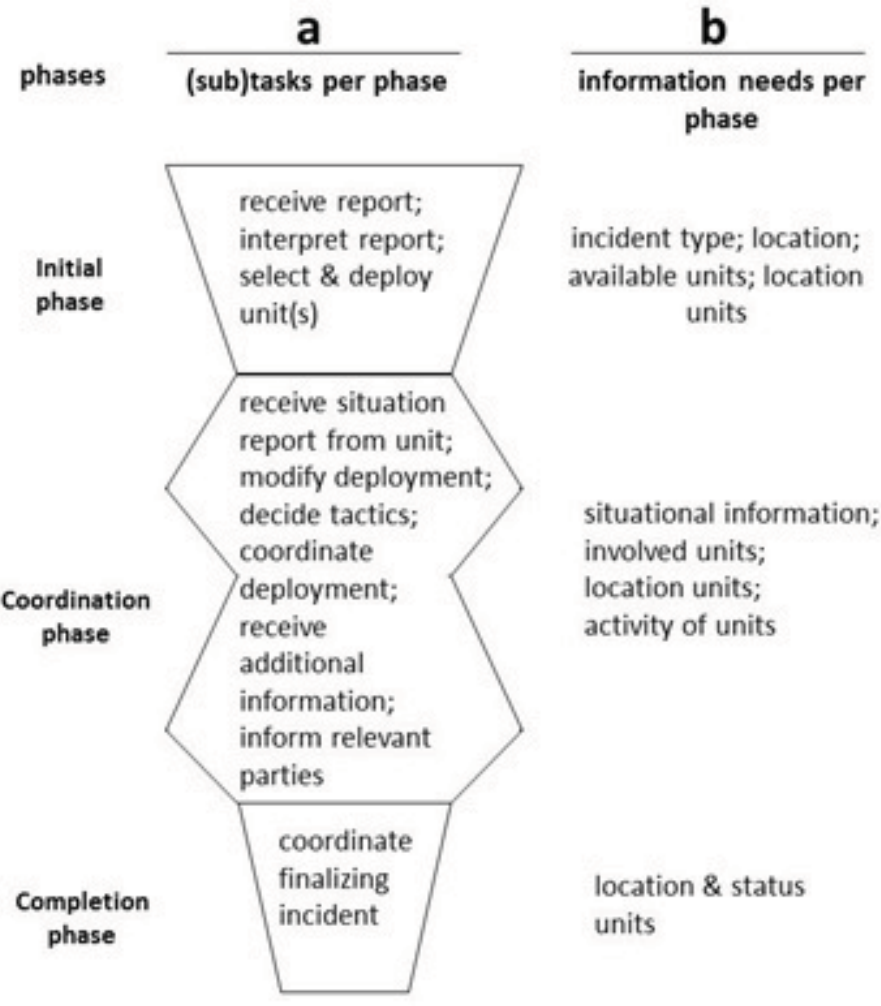

\section{information recorded and presented by the current system per phase * (frame used)}

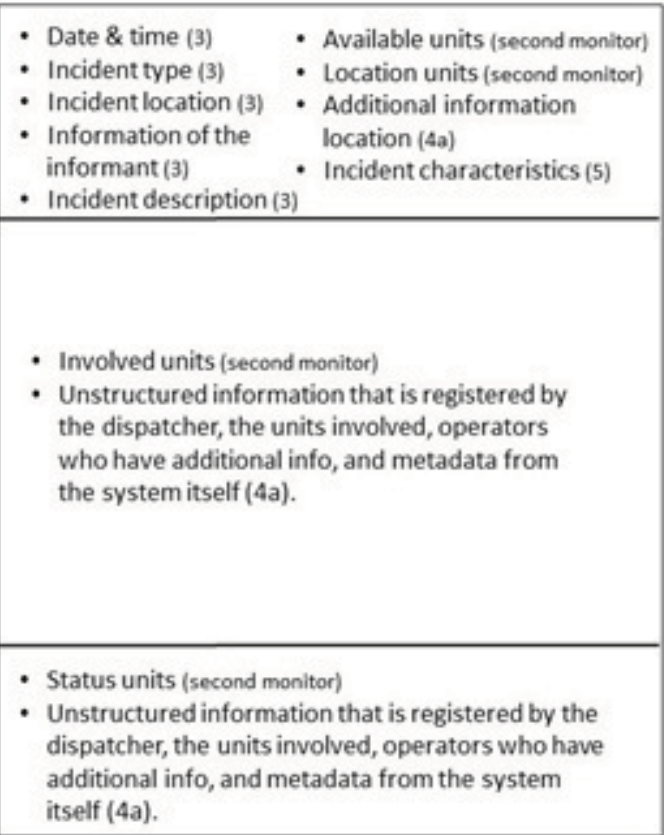

Figure 5: Illustration of the Link between Information Needs and Information Used During the Course of the Task Performance. (Figure created by author)

* The number in brackets indicates the corresponding frame number or the separate second monitor as shown in Figure 4, where the information is shown on the work screen. 
role of IT systems in complex collaborative tasks. The design will then bridge the gap between the information needs of the dispatcher and the information that is available in the IT system for the task performance.

To be able to generalize the research results, it is necessary to determine at what time which devices for coordinating complex tasks are needed most, and how this coordination should be supported by information systems. Furthermore, the design requirements should be validated. It is especially necessary to examine how dynamic, situational information (i.e., explicit agreements, saliences, and precedents) should be recorded and presented in order to fit the known static, generic information that refers to the appropriate procedures.

\section{Further Application}

The consistency of the results of the three studied real-life situations makes it plausible that these design requirements are valid for various work situations, in particular situations where parties with different expertise need to work together for extended periods of time and in varying groups and need static and situational information to form and maintain a good understanding of the actual task situation(s). This applied not only to the coordination centers, but also for multidisciplinary design teams, (medical) home-care teams, and nursing departments in hospitals. When one has captured the operational communication of, the presented method is directly applicable for those settings. Moreover, because of the increasing application of IT - and in particular sensor technology- in more and more practices, professionals need to form and maintain a good understanding of task situations which are enriched by information. When an individuals can determine which static and situational information they need, that person can design a more focused support system to deal with complex situations.

\section{REFERENCES}

Albers, M. J. (2004). Communication of complex information: User goals and information needs for Dynamic web information. New York: Routledge.

Alkemade, M. J. A. (1992). Inspelen op complexiteit: Mens, techniek, informatie en organisatie Responding to complexity: Man, engineering, information and organization]. Zaventum: Samson edrijfsInformatie.

Berndtsson, J., \& Normark, M. (1999). The coordinative functions of flight strips: Air traffic control work revisited. Proceedings of the International ACM SIGGROUP Conference on Supporting Group Work, 101-110.

Beyer, H., \& Holtzblatt, K. (1997). Contextual design: Defining customer-centered systems. San Diego: Elsevier.

Clark, H. (1996). Using language. New York: Cambridge University Press. doi:10.2277/0521561582

Clark, H., \& Schaefer, E. (1987). Collaborating on contributions to conversations. Language and Cognitive Processes, 2(1), 19-41. doi:10.1080/01690968708406350

Clark, H., \& Brennan, S. E. (1991). Grounding in communication. In L. B. Resnick, J. M. Levine \& S. D. Teasley (Eds.), Perspectives on socially shared cognition (pp. 127-149). Washington, DC: American Psychological Association. doi:10.1037/10096-006

Gabris, C., \& Artman, H. (2004). Team situation awareness as communicative practices. In S. Banbury, \& S. Tremblay (Eds.), A cognitive approach to situation awareness: Theory and application (pp. 275-296). Hampshire, England: Ashgate Publishing.

Table 6: Summary of Generic Design Requirements

\begin{tabular}{|c|l|}
\hline $1 a$ & $\begin{array}{l}\text { In the system, it should be possible to record the agreements that are made per report; as far as possible, } \\
\text { this should be done automatically. }\end{array}$ \\
\hline $1 b$ & $\begin{array}{l}\text { In the system, it should be possible to record the parties that made an agreement, as well as the moment this } \\
\text { agreement was made. }\end{array}$ \\
\hline $1 c$ & $\begin{array}{l}\text { In the system, it should be possible to share the agreements made with the parties involved. Preferably, } \\
\text { these parties should be determined in advance. }\end{array}$ \\
\hline 2 & $\begin{array}{l}\text { In the system, it should be possible to attach notes or agreements to specific static, procedural information of } \\
\text { the report in question. For example, how is a certain procedure applied in this particular incident? }\end{array}$ \\
\hline 3 & $\begin{array}{l}\text { The system should be easily searchable. This also means that it should be possible to clearly define the } \\
\text { sequence of events, the corresponding information, notes, agreements, and the setting on a timeline. For } \\
\text { example, information about suspect descriptions should be easily and quickly retrievable. }\end{array}$ \\
\hline $4 a$ & $\begin{array}{l}\text { The situational and generic information that is visible on the screen should fit the current phase of the inci- } \\
\text { dent handling. }\end{array}$ \\
\hline $4 b$ & $\begin{array}{l}\text { Information that is not applicable in the current phase of an incident handling should preferably not be } \\
\text { shown constantly, but should be immediately accessible. For example, information about incident location } \\
\text { and the person reporting the incident. }\end{array}$ \\
\hline 5 & $\begin{array}{l}\text { The system should alert the user to situation changes that may have critical consequences for the overall } \\
\text { procedure. For example, an expected shortage of units for a certain district. }\end{array}$ \\
\hline
\end{tabular}


Garner, M., \& Johnson, E. (2007). Operational communication: A paradigm for applied research into police call-handling. International Journal of Speech Language and the Law, 13(1), 55-75.

Heath, C., \& Luff, P. (1992). Collaboration and control: Crisis management and multimedia technology in London underground line control rooms. Computer Supported Cooperative Work (CSCW), 1(1), 69-94.

Hutchins, E., \& Palen, L. (1997). Constructing meaning from space, gesture, and speech. NATO Advanced Research Workshop on Discourse, Tools, and Reasoning: Situated Cognition and Technologically Supported Environments, Lucca, 160, 23-40.

Kirwan, B., \& Ainsworth, L. K. (1992). A guide to task analysis: The task analysis working group. Boca Raton: CRC Press.

Klein, G., Feltovich, P. J., Bradshaw, J. M., \& Woods, D. D. (2005). Common ground and coordination in joint activity. Organizational simulation (pp. 139-184) New Jersey: John Wiley \& Sons, Inc. doi:10.1002/0471739448.ch6

Lenior, T. M. J. (1993). Analysis of cognitive processes in train traffic control. Ergonomics, 36(11), 1361-1368. doi:10.1080/00140139308968005

Luokkala, P., \& Virrantaus, K. (2014). Developing information systems to support situational awareness and interaction in time-pressuring crisis situations. Safety Science, 63, 191-203.

Mazeland, H. (2003). Inleiding in de conversatieanalyse [Introduction to conversation analysis]. Bussum: Coutinho.

Nova, N., Sangin, M., \& Dillenbourg, P. (2008). Reconsidering Clark's theory in CSCW. Proceedings of the 8th International Conference on the Design of Cooperative Systems, 132-143.

Pikaar, R., Lenior, T., \& Rijnsdorp, J. (1990). Implementation of ergonomics in design practice: Outline of an approach and some discussion points. Ergonomics, 33(5), 583-587.

Randall, D., Harper, R., \& Rouncefield, M. (2007). Fieldwork for design: Theory and practice. London: Springer.

Shannon, C., \& Weaver, W. (1963). Mathematical theory of communication. Champaign: University Illinois Press.

Streefkerk, J. W., Smets, N., Varkevisser, M., \& Mastrigt, S. H. (2014). Future command and control systems should combine decision support and personalization interface features. Proceedings of the 8th Nordic Conference on Human-Computer Interaction: Fun, Fast, Foundational, 266-275.

Suchman, L. (1997). Centres of coordination: A case and some themes. In L. B. Resnick, R. Säljö, C. Pontecorvo \& B. Burge (Eds.), Discourse, tools, and reasoning: Essays on situated cognition (pp. 41-62). New York: Springer.

Suchman, L. (2007). Human-machine reconfigurations: Plans and situated actions. Cambridge; New York: Cambridge University Press.

Suchman, L. (1994). Do categories have politics? Computer Supported Cooperative Work (CSCW), 2(3), 177-190.
Van Beuzekom, M., Boer, F., Akerboom, S., \& Hudson, P. (2010). Patient safety: Latent risk factors. British Journal of Anaesthesia, 105(1), 52-59.

Weigand, H. (2006). Two decades of language/action perspective. Communications of the ACM, 49(5), 45-46.

Winograd, T. (2006). Designing a new foundation for design. Communications of the ACM, 49(5), 71-74.

\section{APPENDIX A}

We selected a large number of handled reports in order to compile a representative collection of operational communication. We used two "inputs": first the assigned priority and second the report type.

As described in the text, the operator interprets all incoming emergency reports and assigns a priority, namely 1 or 2 . Table 7 shows the ratio between the number of priority-1 and priority-2 reports that were recorded in three months. Priority-1 reports generally require more communication than priority- 2 reports. Hence, we selected more priority-1 reports (153) than priority-2 reports $(81)$. We also selected 19 reports with priorities $3-5$ to form a complete picture of the tasks of the dispatcher. Since these reports do not concern emergencies, we did not select those for the content analysis.

The second "input," the report type, shows some consistency with the prioritization. We did select reports based on the type classification, but we also took into account how operators and dispatchers deal with this classification. There is an automatic report-classification system with nine report types. There are also 28 report sub-types, but these are not considered here. The operator can "tick" a type, but he can also "trigger" the system's automatic classification by using the right keywords in the description. As the dispatchers indicated in the interviews, their impression of the report indeed determined the use of the keywords. The story of the person reporting the incident is interpreted and "translated" into the classification terminology of the system.

The available overviews allowed us to determine that the distribution of both the number of reports and the report type was very constant throughout the months. Subsequently, we based our selection of reports on the overviews of reports in three distinct months, and selected the number of reports per type that more or less corresponded with the percentages in those overviews. However, we allowed incidents that require a lot of communication to be overrepresented.

Column 2 of Table 8 shows the percentage of selected reports per type, and the corresponding percentage from the overviews of the three months in brackets. For example, relatively more reports were selected for the three types - property crime, health, and safety \& public order - because for these types of reports, multiple units are usually deployed, and the units and the control room communicate a lot. Our selection includes proportionally fewer reports of the types fire, service, and environment. Even though these types are common, there is hardly any communication between the control room and the units. Moreover, the majority of the fire reports concerned a false alarm, so conversations with this report type were not selected. For the sake of readability, the sub-classifications have been omitted from Table 8 . 
Table 7: Number of Priority-1 and Priority-2 Reports (Recorded Over a Three-Month Period)

\begin{tabular}{|l|l|l|}
\hline Month & Prio-1 & Prio-2 \\
\hline March 2012 & 2963 & 3546 \\
\hline June 2012 & 2913 & 3788 \\
\hline August 2012 & 2766 & 3756 \\
\hline
\end{tabular}

Table 8: Overview of Data Selection in Relation to Representativeness

Column 3 of Table 8 shows how many reports were selected for this study. Columns 4 shows how many reports were analyzed in Step 2, the content analysis of the operational communication, and column 5 shows how many conversations were analyzed in Step 2.

\begin{tabular}{|l|l|l|l|l|}
\hline $\begin{array}{l}\text { Main classification of } \\
\text { report type }\end{array}$ & $\begin{array}{l}\text { Percentage of } \\
\text { selected reports }\end{array}$ & $\begin{array}{l}\text { Number of } \\
\text { selected reports }\end{array}$ & $\begin{array}{l}\text { Analyzed } \\
\text { reports }\end{array}$ & $\begin{array}{l}\text { Analyzed } \\
\text { conversations }\end{array}$ \\
\hline Alarm & $5.53\left(5.29^{*}\right)$ & 14 & 1 & 12 \\
\hline Property Crime & $22.13(15.45)$ & 56 & 4 & 64 \\
\hline Fire & $3.16(1.03)$ & 8 & 0 & 0 \\
\hline Service & $4.35 \quad(5.56)$ & 11 & 0 & 0 \\
\hline Health & $10.28 \quad(5.87)$ & 26 & 2 & 8 \\
\hline Environment & $8.70(25.06)$ & 22 & 0 & 0 \\
\hline Accident & $6.32(8.88)$ & 16 & 1 & 3 \\
\hline Safety \& Public order & $28.85(28.22)$ & 73 & 3 & 130 \\
\hline Traffic & $10.67 \quad(4.62)$ & 27 & 2 & 11 \\
\hline Total & $100.00(100.00)$ & 253 & 13 & 228 \\
\hline$*$ Mean percentage of all reports in three distinct months & & \\
\hline
\end{tabular}




\section{APPENDIX B}

In Table 9, we explain the conversation analysis conventions that were used when transcribing the conversations between the dispatcher and the units.

Table 9: Explanation of Used Transcription Conventions (Mazeland, 2003)

\begin{tabular}{|l|l|}
\hline$()$. & Short silence of less than 0.3 sec. \\
\hline$(.3),(2.6)$ & The length of silence in tenths of seconds. \\
\hline $\begin{array}{l}\downarrow \text { down } \downarrow \\
\downarrow \text { up } \downarrow\end{array}$ & $\begin{array}{l}\text { Local pitch movement, word or syllable between arrows is spoken with a rising }(\downarrow) \text { or lower }(\downarrow) \\
\text { tone. }\end{array}$ \\
\hline $\begin{array}{l}\text { [word } \\
\text { [word }\end{array}$ & Square brackets locate the onset of overlapping talk. \\
\hline word? & Word before ? is spoken with rising tone, not necessarily a question \\
\hline wor- & A hyphen shows moment of cut-off. \\
\hline wo:rd & Colons show a sound stretch. The more colons the longer preceding sound the stretches. \\
\hline $\begin{array}{l}\text { (words) } \\
\text { word= } \\
=\text { word }\end{array}$ & The transcriber is uncertain about the utterance between parentheses. \\
\hline $\begin{array}{l}\text { word }, \\
\text { WORD }\end{array}$ & $\begin{array}{l}\text { Underlined words/parts are stressed, words/parts in capitals are spoken out more loudly than } \\
\text { surrounding talk. }\end{array}$ \\
\hline $\begin{array}{l}\text { >word word }< \\
<\text { word word }>\end{array}$ & $\begin{array}{l}\text { Talks between inwards arrows have faster speech, talks between outward arrows have slower } \\
\text { speech. }\end{array}$ \\
\hline$($ text) $)$ & Contextual information from the transcriber \\
\hline
\end{tabular}

